\title{
Educação de Jovens e Adultos na PERSPectiva de DUAS ESCOLAS EM CUIABÁ
}

\author{
YOUTH AND ADULT EDUCATION IN THE PERSPECTIVE OF TWO SCHOOLS \\ IN CUIABÁ
}

DOI: http://dx.doi.org/10.23926/RPD.2526-2149.2019.v4.n2.p834-851.id538

\author{
Maria Geni Pereira \\ Bilio \\ Mestranda em Ensino \\ (UNIC) \\ Professora de I a IV da \\ Prefeitura Municipal de \\ Várzea Grande \\ genibilioprofessora@gmail.c \\ om
}

\section{Nair Mendes de \\ Oliveira}

Mestranda em Ensino

(UNIC)

Pedagoga no Instituto Federal

de Mato Grosso

(PROEN/IFMT)

nmoliveira.5@gmail.com

\section{Maria das Graças \\ Campos}

Doutora em Políticas

Públicas e Formação Humana

(UERJ)

Professora do IUNI (UNIC)

professoramatogrosso@gmail

.com

\section{Enerci Candido \\ Gomes}

Mestre em Ensino (UNIC)

Professora da Rede Estadual

de Educação de Mato Grosso

(SEDUC/MT)

candidoenerci@yahoo.com.br
Resumo: Este artigo faz parte de uma pesquisa maior desenvolvida pelo Programa de Pós-Graduação em Ensino da UNIC- Universidade de Cuiabá em parceria com o Instituto Federal de Educação, Ciência e Tecnologia de Mato Grosso-IFMT. A pesquisa de qualitativa tem por objetivo analisar a maneira pela qual se dá a abordagem curricular dessa modalidade de ensino, procurando evidenciar a percepção discente acerca dos quesitos estruturais relativos à esfera educacional pertinente ao currículo que perpassa o processo formativo dos alunos da Educação de Jovens e Adultos (EJA) em duas escolas públicas do município de Cuiabá. Elegemos como metodologia o uso de fontes documentais e bibliográficas, sendo que a coleta de dados foi realizada via aplicação de questionário sócio econômico aos alunos das escolas lócus da pesquisa, utilizando como técnica de investigação o grupo focal. Como resultado foi possível compreender a atual intenção formativa da EJA nas escolas em foco, para repensar as dimensões teóricas e práticas no que se refere ao currículo desenvolvido na EJA nas escolas da pesquisa. Constatamos que, ao longo do tempo, a modalidade de ensino em tela tem sido desvalorizada, uma vez que as políticas públicas direcionadas para a mesma não apresentam preocupação no que se refere às suas especificidades, pois os atores sociais que as compõem são indivíduos que não tiveram a oportunidade de concluir seus estudos em idade regular, que deve ser levado em consideração no seu processo formativo, ainda que tardio.

Palavras-chave: Políticas Públicas. Oportunidades. Educação de Jovens e Adultos.

\begin{abstract}
This article is part of a larger research developed by the Graduate Program in Teaching of UNIC - University of Cuiabá in partnership with the Federal Institute of Education, Science and Technology of Mato GrossoIFMT. The qualitative research aims to analyze the way in which the curricular approach of this teaching modality takes place, seeking to highlight the student perception about the structural issues related to the educational sphere pertinent to the curriculum that permeates the formative process of the students of Youth Education. Adults (EJA) in two public schools in the city of Cuiabá. We chose as methodology the use of documentary and bibliographic sources, and the data collection was performed by applying a socioeconomic questionnaire to the students of the locus of the research, using the focus group as a research technique. As a result it was possible to understand the current formative intention of EJA in the schools in focus, to rethink the theoretical and practical dimensions regarding the curriculum developed in EJA in the research schools. We have noticed that, over time, the teaching modality on screen has been devalued, since the public policies directed to it have no concern regarding its specificities, because the social actors that compose them are individuals who do not They had the opportunity to complete their studies at a regular age, which should be taken into account in their formative process, albeit late.
\end{abstract}

Keywords: Public Policies. Opportunities Youth and Adult Education. 


\section{INTRODUÇÃO}

A Educação de Jovens e Adultos (EJA) no Brasil apresenta disparidade entre o número de ingressantes e concluintes. As estatísticas revelam que o abandono escolar é um ato corriqueiro por muitos matriculados. O alto índice de pessoas analfabetas é considerável, mesmo com a criação de políticas públicas específicas para essa modalidade de ensino. A situação é crítica e demandará muito investimento na área para minimizar esse problema que acompanha a sociedade brasileira desde o início da colonização.

Ainda que a questão curricular consista em uma das preocupações da agenda educativa no século XXI, tendo em vista a promulgação da Resolução ${ }^{\circ} 3$ de 15 de junho de 2010, que institui Diretrizes Operacionais para a Educação de Jovens e Adultos nos aspectos relativos à duração dos cursos e fixação de idade mínima para ingresso nos cursos de EJA nas escolas brasileiras em todos os níveis de ensino, ainda existe uma grande lacuna a ser preenchida nesse contexto, (MEC, 2010).

O direito à Educação, conquistado após anos de lutas pela sociedade civil organizada, foi um grande passo para a evolução do cidadão como um ser de direito após Constituição Federal de 1988, mas ainda existem muitas indagações sobre onde foi o ponto de partida da relação entre a diversidade e o currículo para os profissionais que atuam no campo da educação, por atravessarem os diversos níveis de ensino desde a educação básica à educação profissional, incluindo a EJA. Faz-se necessário uma reeducação do olhar sobre o "outro" e sobre nós mesmos a partir das diferenças para superar e construir políticas públicas, bem como, rever as práticas pedagógicas e curriculares nas quais a diversidade seja uma dimensão constitutiva do currículo, e do planejamento das ações nas relações estabelecidas na escola (ARROYO, 2006, p. 26).

A fim de conseguir alcançar esse objetivo, todos nós que atuamos e ocupamos da escola somos desafiados a rever o ordenamento curricular e as práticas pedagógicas, entendendo que estes não representam apenas uma determinada visão de conhecimento que pode excluir o "outro" e suas diferenças, mas também e, sobretudo, uma determinada visão dos alunos (Arroyo, 2006, p.54).

A Lei de Diretrizes e Base da Educação - LDB, Lei No 9394/96, assegura o direito às pessoas que não frequentaram a escola no ensino regular, considerando as diversidades de interesses e condições de vida do cidadão. Esse direito já havia sido conquistado junto à Constituição Federal de 1988, sendo reforçado na LDB 9394/96.

Os documentos oficiais direcionam como e onde devemos usá-los, pois desde a primeira Constituição até a atual Base Nacional Comum Curricular - BNCC definem a direção que a 
educação brasileira deve seguir e o que abordar no sentido geral, sendo que, cada unidade da federação é responsável pela elaboração e inserção no currículo, dos conteúdos regionais de acordo com a realidade local.

Embora a escola, que atualmente tem demonstrado preocupação com os direitos adquiridos no decorrer da história, percebemos que ainda tem muito a evoluir no sentido de construir um currículo que atenda as especificidades da educação de jovens e adultos, haja visto a existência de estudantes de diferentes faixas etárias demandando assim, práticas escolares diferentes:

As mudanças próprias dessa fase da vida implicam a compreensão do adolescente como sujeito em desenvolvimento, com singularidades e formações indenitárias e culturais próprias, que demandam práticas escolares diferenciadas, capazes de contemplar suas necessidades e diferentes modos de inserção social, (Ministério da Educação, 2016, p.56).

Neste sentido, abordamos o currículo na visão dos discentes da EJA a fim de podermos identificar o que é importante trabalhar em sala de aula, levando em conta a necessidade dos atores sociais pertencentes à modalidade de ensino em tela, valorizando suas experiências vividas, tornando assim a educação mais significativa e de qualidade.

Para facilitar a construção de uma educação significativa faz-se necessário se colocar no lugar do estudante fazendo uma indagação: Existe consonância entre a teoria e a prática desenvolvidas em sala de aula? O que o estudante está aprendendo vai ao encontro das suas necessidades?

Procura-se conhecer a percepção do estudante da EJA sobre a educação recebida, no sentido de perceber se ele participa ativamente da construção de uma educação, cujo objetivo é o desenvolvimento integral do ser humano, lhe oportunizando ascensão social digna, devolvendo o que lhe foi tirado via exclusão social. Sabe-se que por meio da educação se constrói dignidade, onde podemos desenvolver nossas habilidades e construir um mundo melhor.

A pesquisa foi desenvolvida em duas escolas públicas em Cuiabá, sendo que uma delas situa-se em um bairro periférico da cidade e outra na região central. A escola localizada na região centro sul da cidade, desenvolve o Ensino Fundamental, Ensino Médio e EJA com ensino regular. No centro da cidade de Cuiabá temos o CEJA - Centro de Educação de Jovens e Adultos, que oferta somente a Educação de Jovens e Adultos com metodologia diferenciada conhecida por Carga Horária Etapa. 


\section{REVISÃO DE LITERATURA}

\subsection{COMPREENDENDO O CENÁRIO DA EDUCAÇÃO DE JOVENS E ADULTOS}

A Educação de Jovens e Adultos avançou no sentido da importância das suas diferentes funções, após sua incorporação na Constituição Federal de 1988 por meio do Art. 205 que destaca, "toda e qualquer educação visa ao pleno desenvolvimento da pessoa, seu preparo para o exercício da cidadania e sua qualificação para o trabalho".

A Lei de Diretrizes e Bases da Educação Nacional - LDB nº 9.394/96 abrange todos os educandos e, com isso, a Educação de Jovens e Adultos ganha força por representar uma parte da sociedade que luta pela igualdade de direitos de acesso à educação como bem social. Ressalta-se que a LDB no Título V, capítulo II, como modalidade da educação básica, superando sua dimensão de ensino supletivo, regulamentando sua oferta a todos aqueles que não tiveram acesso ou não concluíram o ensino fundamental em tempo e idade regular. Essa modalidade de ensino requer um olhar mais atento para a questão curricular, por ser um tema em discussão na atualidade.

Não é fácil a compreensão sobre currículo tendo em vista a diversidade que engloba esse tema. No contexto histórico em que o Brasil está vivendo, o currículo tem passado por diversas alterações que não deixa evidente qual será a concepção de currículo que os documentos oficiais irão adotar.

\footnotetext{
Neste momento utilizaremos Michael Apple (2002, p.59), nesse cenário conceitua-se currículo, aderindo à ideia de que: o currículo nunca é apenas um conjunto neutro de conhecimentos, que de algum modo aparece nos textos e nas salas de aula de uma nação. Ele é sempre parte de uma tradição seletiva, resultado da seleção de alguém, da visão de algum grupo, acerca do que seja conhecimento legítimo.
}

Não podemos falar sobre Educação de Jovens e Adultos sem mencionar o nome do grande educador brasileiro, Paulo Freire. Cuja concepção baseia-se na ideia de libertar o aluno de um ensino alienante. $\mathrm{O}$ aluno depende disso para dar rumo ao aprendizado. A percepção do autor é a de que o processo de educação e formação de uma consciência humana busca a compreensão do mundo em que vive; na perspectiva de que "formar é mais do que puramente treinar o educando no desempenho de destrezas" (FREIRE, 1996). É necessário perceber a importância da educação problematizadora para humanizar a sociedade. Para tanto, faz-se necessário o diálogo entre educador e educando que é iniciado pelo planejamento dos conteúdos associado ao cotidiano dos alunos, desenvolvendo, assim, uma conexão com a realidade em que eles vivem. 
Mesmo exilado, Paulo Freire como "cidadão do mundo", semeou suas ideias falando sobre a relação entre educação, política, imperialismo e libertação.

\begin{abstract}
Considerado como o filósofo inaugural da pedagogia crítica, Freire conseguiu proceder a uma reorientação global da pedagogia, direcionando-a no sentido duma política radical de luta histórica, perspectiva que desenvolveu como projeto de vida. Aquilo que hoje é denominado 'política de libertação' tem vital significação para ativistas da educação no mundo todo, e para o que Paulo Freire contribuiu de modo pioneiro e fundamental (MCLAREN, 1999, p.16-17).
\end{abstract}

Partimos do pressuposto de que a escola consiste em um espaço onde ocorre a construção do conhecimento. A educação tem início no âmbito familiar e se complementa na escola onde será realizada a sistematização do conhecimento, levando em consideração as experiências vividas em outros espaços da sociedade, uma vez que a educação também é fruto do ambiente em que a pessoa vive.

Assim, construir uma educação de qualidade é prioritariamente repensar seus conteúdos e programas. Merecem reflexão os conteúdos a serem ensinados e aprendidos, nos quais muitas vezes são consideradas expressões máximas da função social da escola. A EJA, no cumprimento de suas intenções inclusivas, em uma perspectiva macro, foge de ações de cunho neoliberal, por compreender que quando os saberes e as habilidades requeridos pela economia e pelo emprego mudam, a instituição escolar tem de mudar (ARROYO, 2013).

Mesmo diante da importância de sua dimensão, o currículo da EJA traz consigo a marca de ser mais fácil por sofrer redução de conteúdos ao longo do tempo, possibilitando um trabalho didático diferenciado, que respeita o tempo e conhecimento dos alunos (OLIVEIRA, 2009).

Neste sentido, somando todas as dimensões existentes da EJA na escola, a relação entre o processo de ensino e aprendizagem do currículo é flexível por isso se torna relevante. Para Moreira e Candau (2007), a filosofia que está subjacente às escolhas pedagógicas, os conteúdos trabalhados nas escolas normalmente sofrem a tendência de ser voltada à avaliação e à apreciação desse processo, via de regra, utilizando notas, conceitos e conselhos escolares. Assim para os autores:

Tendemos a ensinar conhecimentos que possam ser de algum modo, avaliados. Mas, é claro, nem todos os conteúdos são avaliados da mesma forma. Os que historicamente têm sido vistos como os mais "importantes" costumam ser avaliados segundo padrões vistos como mais "rigorosos", ainda que não se problematize quem ganha e quem perde com essa "hierarquia". (MOREIRA; CANDAU, 2007, p.25)

$\mathrm{Na}$ busca por atender ao processo formativo do trabalhador em perspectiva integral, foi criado no ano de 2005 o Proeja- Programa Nacional de Integração da Educação Profissional com a Educação Básica na Modalidade de Educação de Jovens e Adultos, que foi ressignificado 
no em 2006 pelo governo à época. Segundo o Ministério da Educação (2006), o PROEJA consiste em um programa composto por duas diferentes demandas, abordado no Documento Base: "Educação de Jovens e Adultos no Brasil" e "Percursos descontínuos e em descompasso em relação à Educação Básica no Estado brasileiro", tendo como enfoque a integração entre o ensino médio e os cursos técnicos de nível médio.

A outra parte do programa enfatiza o acesso, a qualidade e a permanência no ensino fundamental e as suas implicações também apontando para a necessidade de integrar os anos finais do ensino fundamental na modalidade EJA, com a Educação Profissional (formação inicial e continuada), a fim de tornar essa etapa de escolarização mais significativa e abrangente (MINISTÉRIO DA EDUCAÇÃO, 2007).

O objetivo do programa é fornecer conhecimentos necessários ao aluno da EJA melhorando, assim, suas condições sociais e a inserção no mercado de trabalho.

\subsection{A EJA: UMA RETROSPECTIVA}

Segundo a história da educação brasileira a Educação de Jovens e Adultos teve início com os jesuítas durante os primeiros séculos de colonização, mas somente em 1979 foram criados os primeiros cursos para adultos analfabetos nos quais o pré-requisito estava atrelado à liberdade e ao sexo (masculino).

Com o alto índice de analfabetismo no país (cerca de $82 \%$ da população acima de cinco anos), a partir de 1891 quando a educação passou a ser de responsabilidade dos municípios e província ocorreu a oferta de cursos noturnos de instrução primária, em 1930 marca seu início na história da educação brasileira, em meados de 1940, se afirmou como um problema de política Nacional. (HADDAD e DI PIERRO, 2000).

Segundo Haddad e Di Pierro (2000, p.116), o ensino supletivo de acordo com a Lei 5.692, visava constituir "uma nova concepção de escola" em uma "nova linha de escolarização não formal, pela primeira vez entendida no Brasil e sistematizada em capítulo especial de uma lei de diretrizes nacionais".

Com a criação do Movimento Brasileiro de Alfabetização - MOBRAL em 1967, acompanhado pelo ensino supletivo, cujo objetivo principal era ensinar o cidadão a ler e escrever funcionalmente. Em virtude disso, foram constatados avanços irrelevantes durante esse programa, terminou no Regime Militar em 1985 e criou em seu lugar a (Fundação Nacional para Educação de Jovens e Adultos) - Fundação EDUCAR. (PAIVA 1983). 
O método adotado pelo Mobral, mesmo tendo objetivos afins com o método de Paulo Freire se diferenciava porque sua preocupação se restrita a ensinar a ler e escrever, e Freire sempre fora um educador que lutou pelo fim da educação elitista, com o objetivo de desenvolver uma educação libertadora e democrática, que visava partir da realidade vivida do aluno. (ARANHA 1996).

\begin{abstract}
O projeto MOBRAL permite compreender bem esta fase ditatorial por que passou o país. A proposta de educação era toda baseada nos interesses políticos vigentes na época. Por ter de repassar o sentimento de bom comportamento para o povo e justificar os atos da ditadura, esta instituição estendeu seus braços a uma boa parte das populações carentes, através de seus diversos Programas. (BELLO 1993, p 209).
\end{abstract}

Paulo Freire foi o grande responsável pelo método que consistia em uma proposta de alfabetização de jovens e adultos, que utilizava o diálogo como método principal para desenvolver junto aos alunos uma aprendizagem significativa. Sua proposta tinha como base a educação popular, educação do povo, com e para o povo, com intenção de desenvolver um trabalho pedagógico tendo como alicerce a realidade vivenciada pelas pessoas, com o objetivo de transformar o mundo em que elas vivem.

Com o fim da Ditadura Militar e de acordo com a Constituição Federal de 1988, após inúmeras formulações a ação política pedagógica teve como consequências a garantia o princípio da educação de jovens e adultos como direito fundamental adquirido e não respeitado desde 1948. Organizado e promulgado na LDB n 9394/96, dando a essa modalidade de ensino os meios formais com o reconhecimento tanto em suas teorias como na sua prática, (GAUTHIER E TARDIF, 2010).

Em 1990, foi extinta a Fundação EDUCAR no mesmo ano a UNESCO designou como sendo o Ano Internacional da Alfabetização e o governo federal fica livre de financiar a educação de jovens e adultos, finalizando assim os programas de alfabetização existentes, (OLIVEIRA, 2007).

Atualmente, a EJA é organizada pelo Parecer 11/2000 e pela Resolução 01/2000 do Conselho Nacional de Educação. Nas audiências do Conselho, os Fóruns participam efetivamente para discutir as Diretrizes Curriculares para a EJA. Este ponto de partida fez toda a diferença, pois conforme o Parecer 11/2000 no Brasil,

[...] país que ainda se ressente de uma formação escravocrata e hierárquica, a EJA foi vista como uma compensação e não como um direito. Esta tradição foi alterada em nossos códigos legais, na medida em que a EJA, tornando-se direito, desloca a ideia de compensação substituindo-a pelas de reparação e equidade. Mas ainda resta muito caminho pela frente a fim de que a EJA se efetive como uma educação permanente a serviço do pleno desenvolvimento do educando (BRASIL, 2000 p 66). 
Segundo Haddad (2008), as reformas do Estado, assim como dos sistemas de educação, promoveram a adoção de pacotes institucionais conveniados entre as Secretarias de Estado da Educação e a Fundação Roberto Marinho. Essas reformas deram origem a uma nova identidade da EJA, ampliada, fragmentada, heterogênea e complexa, revelando-se através das diferentes atividades e experiências desenvolvidas com recursos de Fundo de Amparo ao Trabalhador (FAT), direcionadas à alfabetização, à educação básica, ou aos cursos profissionalizantes de nível básico.

No governo Luís Inácio Lula da Silva (2003-2010), o crescimento foi direcionado ao ensino profissionalizante, incorporando ao financiamento do FUNDEB, dentre outros. No período do governo de Luís Inácio Lula da Silva (2003-2010), a expansão ocorreu com a educação profissional, referindo-se à alfabetização de jovens e adultos como área de interesse prioritário, incorporaram-se as matrículas ao financiamento do FUNDEB e desenvolveram-se várias entre 2002 a 2006 voltadas aos jovens e adultos trabalhadores. Dentre estas se destacam: Brasil Alfabetizado, Saberes da Terra, Proeja, Escola de Fábrica, Exame Nacional para Certificação de Competências de Jovens e Adultos, ENCEJA, PRONERA, PROEP (Ministério da Educação e Ministério do Trabalho), Plano Nacional de Qualificação, PNQ (MTE), Programa de Assistência e Cooperação das Forças Armadas à Sociedade Civil/Soldado Cidadão (Ministério da Defesa) KUENZER (2006).

Á poucas políticas direcionadas à EJA, e vêm priorizando programas de institucionalidade, voltadas à alfabetização de adultos a promoção de escolaridade e/ou à educação profissionalizante. Surge então o PROJOVEM - Programa Nacional de Inclusão de Jovens: Educação, Qualificação e Ação Comunitária, voltado para conclusão/ certificação do ensino fundamental e formação profissional para jovens entre 18 e 29 anos, (VENTURA 2007).

\section{Metodologia}

Toda metodologia ocupa um lugar central no interior das teorias; Minayo, (2001, p. 148), distingue a forma exterior com que muitas vezes é abordado tal tema (como técnicas e instrumentos) do sentido generoso de pensar a metodologia como a articulação entre conteúdos, pensamentos e existência. Pode-se afirmar que é decorrente de um problema que se desenvolve toda investigação, este é consequência de inquietações por parte da pesquisadora, onde é feita a articulação de conhecimentos anteriores, com novos referenciais.

Para atender aos objetivos propostos para esta investigação, elegemos como metodologia a pesquisa qualitativa, bibliográfica e documental, utilizando como técnica de 
investigação qualitativa o grupo focal; tendo em vista que iremos pesquisar a abordagem curricular desenvolvida junto aos alunos da Educação de Jovens e Adultos nas Escolas Estaduais lócus da pesquisa, aqui referidas como escola A e B; a primeira localizada em bairro periférico e a segunda na região central - ambas na cidade de Cuiabá/MT.

A pesquisa bibliográfica se configura como sendo o exame de materiais de natureza diversa, que ainda não receberam um tratamento analítico, ou que podem ser reexaminados, criando novas interpretações complementares, atividade localização de fontes, para coletar dados gerais ou específicos a respeito de determinado tema. É um componente obrigatório para qualquer pesquisa, na visão de Lakatos,

A pesquisa bibliográfica permite compreender que, se de um lado a resolução de um problema pode ser obtida através dela, por outro lado, tanto a pesquisa de laboratório quanto a de campo (documentação direta) exigem, como premissa, o levantamento do estudo da questão que se propõe a analisar e solucionar. A pesquisa bibliográfica pode, portanto, ser considerada também como o primeiro passo de toda pesquisa científica. (LAKATOS e MARCONI 1992, p. 44).

Diante do exposto, a pesquisa qualitativa surge com o advento da fenomenologia, que enfatiza o componente subjetivo do comportamento das pessoas. Bogdan e Biklen (1994), afirmam que o pesquisador, ao utilizar a abordagem qualitativa, faz uso de um conjunto de asserções que diferem das que são utilizadas quando se estuda o comportamento humano com o objetivo de descobrir fatos e causas. A opção pela metodologia qualitativa corrobora com a definição de Bogdan e Biklen (1994: p. 16) para os quais pesquisa qualitativa é compreendida como:

[...] um termo genérico que agrupa estratégias de investigação que partilham de determinadas características. Os dados recolhidos são [...] ricos em pormenores descritos relativos a pessoas, locais e conversas e de complexo tratamento estatístico.

A maior dificuldade para o desenvolvimento da pesquisa foi referente ao levantamento de dados, primando pelo significado da construção das percepções dos sujeitos e não somente pelos os resultados e o produto final. Tal fundamentação encontra respaldo nas características básicas propostas por Bogdan e Biklen (1994).

Esses autores compartilham a ideia de que para a realização de uma pesquisa na abordagem qualitativa os dados sejam coletados em seu ambiente natural, sem nenhum tipo de manipulação intencional; todos os dados são considerados importantes e apresentados de forma descritiva; o pesquisador tem sua atenção mais voltada ao processo do que ao resultado; o pesquisador se preocupa com o significado que o participante dá às coisas e à sua própria vida e, a análise dos dados coletados parte de uma visão mais ampla para uma mais focada. A 
natureza da pesquisa está proporcionando, contato com os estudantes pesquisados, por meio do diálogo, esclarecendo dúvidas, num processo dialético de interação e reflexão.

A pesquisa com grupos focais tem por objetivo captar, a partir das trocas realizadas pelo grupo, conceitos, sentimentos, atitudes, crenças, experiências e reações, de um modo que não seria possível com outros métodos, como, por exemplo, a observação, a entrevista ou questionários. $\mathrm{O}$ grupo focal permite fazer emergir uma multiplicidade de pontos de vista e processos emocionais, pelo próprio contexto de interação criado, permitindo a captação de significados que, por outros meios, poderia ser difícil de manifestar; (MORGAN e KRUEGER 1993).

Assim, a pesquisa se orientou pela combinação de diferentes técnicas que permitiram compreender a realidade; que focou um fenômeno no interior de um dado contexto, compreendendo o que há de particular no fenômeno e o que foi determinado pelo ambiente estudado.

Objetivando perceber os principais conceitos e implicações do texto da lei, usou-se da análise documental, que se refere à pesquisa qualitativa consiste na possibilidade de realização a partir de documentos que não receberam tratamento analítico contemporâneo ou retrospectivos, considerados cientificamente autênticos, constituindo uma técnica importante na pesquisa qualitativa, seja complementando informações obtidas por outras técnicas, seja desvelando aspectos novos de um tema ou problema. Trata-se de uma técnica decisiva para a pesquisa em ciências sociais e humanas, sendo indispensável porque a maior parte das fontes escritas, ou não, são quase sempre a base do trabalho de investigação. Para Lüdke (1986, p. 38),

[...] a análise documental pode se constituir numa técnica valiosa de abordagem de dados qualitativos, seja complementando as informações obtidas por outras técnicas, seja desvelando aspectos novos de um tema ou problema.

Os dados coletados nas duas escolas tiveram rigoroso tratamento para extrair o melhor de cada grupo, e em seguida fazer a comparação entre as duas escolas que utilizam a mesma modalidade (EJA), mas com estratégias diferenciadas. Os dados serão mostrados através de gráfico para melhor visualização do resultado.

Inicialmente foram feitos contato a equipe gestora das escolas em questão, para solicitar permissão para realizar a pesquisa. $O$ contato com os estudantes ocorreu com a parceira da professora de Inglês. Durante suas aulas podemos dialogar com os estudantes e dialogar sobre alguns pontos importantes para definição dos encontros do grupo focal. Foram realizadas 
algumas reuniões e aplicação do questionário socioeconômico quando também foi feito um levantamento do perfil dos jovens que iriam participar da pesquisa.

No trabalho de pesquisa realizado no Centro de Educação de Jovens e Adultos - Ceja Professor Antônio Cesário de Figueiredo Neto, localizado na região central de Cuiabá, o processo aconteceu de forma diferente. Após autorização para realizar a pesquisa, a coordenadora sugeriu que desenvolvesse um trabalho junto ao professor de Filosofia, tendo em vista a forma diferenciada da oferta da EJA. Com o auxílio do docente foram realizados alguns encontros com os estudantes para aplicação do questionário socioeconômico e realização do grupo focal.

\section{AnÁlise dos Resultados}

A pesquisa foi desenvolvida com 16 alunos, incluindo a aplicação do questionário e a realização do grupo focal. Os dados a seguir foram extraídos dos questionários socioeconômicos realizados com os alunos sujeitos da pesquisa que está em andamento e que serão demonstradas em forma de gráficos. O Gráfico 1 evidencia a distribuição por sexo dos alunos participantes da pesquisa.

Gráfico 1 - Distribuição dos alunos da EJA em relação ao sexo

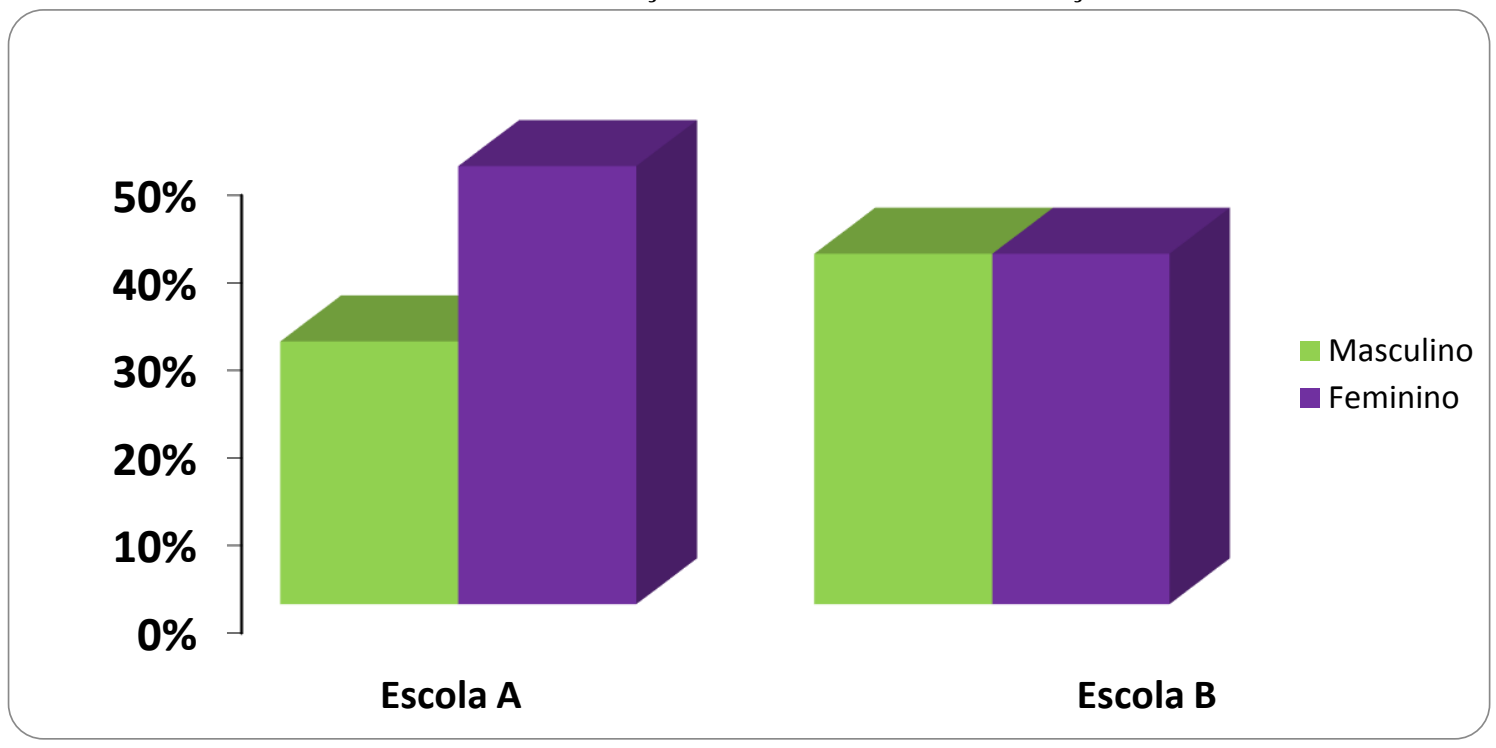

Fonte: elaborado pela pesquisadora

O gráfico acima comprova que a pesquisa foi feita com grupo de alunos, em que a maioria dos participantes da escola localizada na periferia é do sexo feminino. Na escola central a participação dos alunos se equiparou tanto à mesma quantidade do sexo masculino quanto á do sexo feminino. 
No decorrer da investigação foram observados vários aspectos dos estudantes das duas escolas uns visíveis pelo comportamento dos deles e outros pelas respostas dos questionários, além da observação da participação dos mesmos durante a realização do grupo focal. Durante o tempo de com os estudantes das duas escolas constatamos pensamentos semelhantes, contraditórios e aproximados relativos à percepção do currículo desenvolvido na EJA nas duas escolas pesquisadas.

Inicialmente foi delimitada uma faixa etária para a seleção dos atores sociais que participariam das entrevistas e grupo focal, mas no decorrer da pesquisa percebemos que nessa modalidade de ensino é complicada essa restrição, porque a participação é voluntária e nem sempre quem quer participar tem a idade exigida, por isso ficando estabelecida idade a partir de 18 anos, o gráfico abaixo evidencia a idade dos alunos pesquisados. O Gráfico 2 demonstra a faixa etária de idade dos participantes.

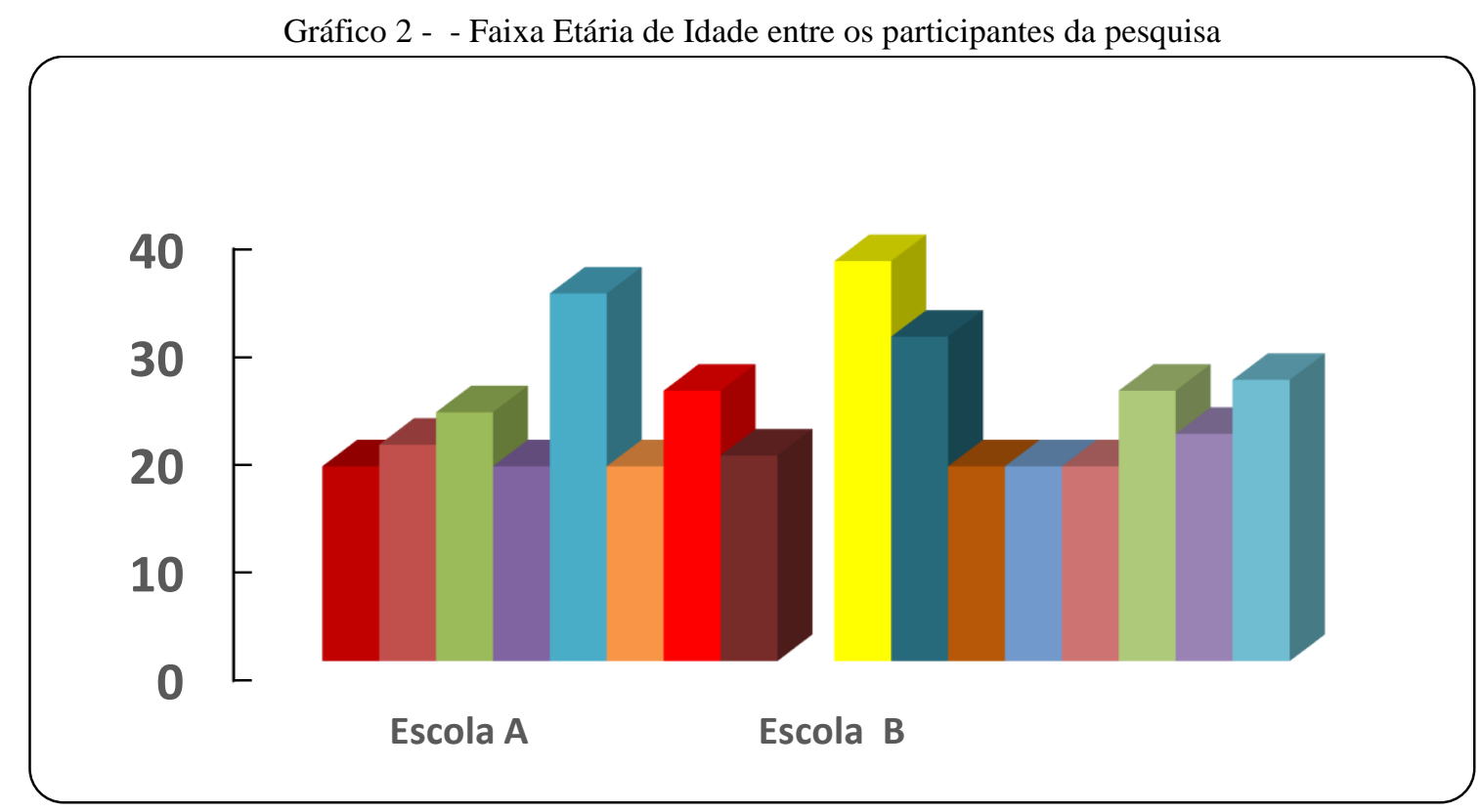

Fonte: elaborada pela pesquisadora

Considerando a faixa etária dos alunos, constata-se não existir idade máxima para voltar a estudar. Nunca é tarde para recomeçar os estudos. Mas pode-se observar que a média de idade dos alunos está entre 20 e 30 anos de idade, provavelmente pelo fato, de nesse período ingressarem no mercado de trabalho. Este dado ficou evidente durante a pesquisa, é um dos maiores motivos para a desistência dos estudos, uma vez que o trabalho consiste em prioridade, em função da necessidade de subsistência. Nesse contexto, nosso país apresenta carência no que diz respeito a políticas públicas, adotadas mais na perspectiva de interesses assistencialistas 
e compensatórias, contradizendo o seu verdadeiro significado em relação à Educação de Jovens e Adultos, sentido que se refere a:

Toda educação destinada àqueles que não tiveram oportunidades educacionais em idade própria ou que a tiveram de forma insuficiente, não logrando alfabetizar-se e obter conhecimentos básicos correspondentes aos primeiros anos do curso elementar, (PAIVA, 1987, p. 16).

Durante a realização do grupo focal nas duas escolas uma das questões discutidas foi sobre a maior dificuldade dos alunos em frequentar a escola. A maioria das respostas apontava para a questão de compatibilizar horários de trabalho com a escola. Tanto na escola de ensino regular, como na escola que utiliza a carga horária etapa (onde o horário é mais flexível do que na outra) o fenômeno se apresenta com a mesma característica.

A dificuldade em administrar o horário também foi um dos pontos fortes que os fizeram desistir de estudar em algum momento de sua vida, quando muitos precisaram tinham que trabalhar para ajudar no sustento da família e desistiam dos estudos. O gráfico 3 apresenta dado de interrupção dos estudos em algum momento de sua vida, pois, por algum motivo os estudantes abandonaram a escola e somente agora, pela necessidade estão retornando.

Gráfico 3 - Fase da vida que abandonou a escola

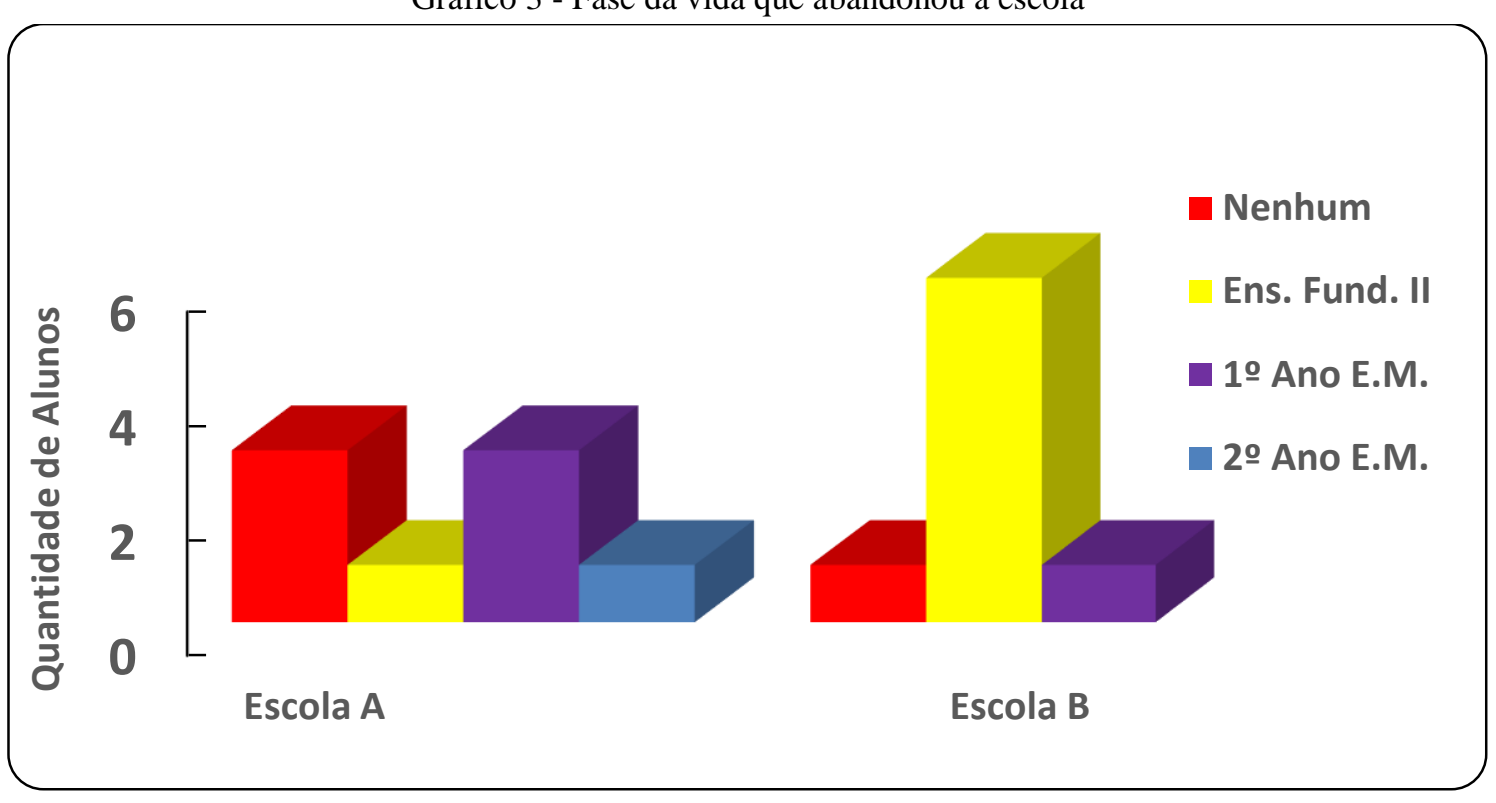

Fonte: elaborada pela pesquisadora

Fica evidente a importância da integração entre trabalho e educação em uma sociedade dividida em classes, pois o fenômeno está relacionado à atividade de autodesenvolvimento e auto realização da existência humana, sendo uma necessidade essencial para efetivar o intercâmbio material entre o homem e a natureza e, portanto, de manter a vida humana, onde a educação representa um instrumento do processo de humanização, (MARX; ENGELS, 2002). 
O mais importante nesse instante é a vontade dos estudantes em superar as dificuldades e conquistar o seu espaço nessa sociedade capitalista tão competitiva e injusta.

\title{
4.1. OS SUJEITOS DA PESQUISA
}

Os sujeitos envolvidos nesta investigação foram dezesseis alunos da EJA de duas escolas estaduais de Cuiabá/MT. Por meio de questionários a pesquisadora obteve as informações no que se refere à visão dos alunos em relação à escola e ao ensino propriamente dito. As turmas envolvidas foram três turmas do $1^{\circ}$ e $2^{\circ}$ Anos do Ensino Médio da modalidade EJA nas duas escolas onde os alunos foram convidados a participar da pesquisa, no total em 16 alunos nas duas escolas lócus da pesquisa sendo nomeada a escola localizada no bairro periférico de "escola A" e a escola central de "escola B".

Ao entrar em contato com os alunos pesquisados via escola, fomos informadas da desistência de alguns após a greve. Diante da informação da escola "A”, procuramos localizar os dois alunos desistentes para saber as razões para tal decisão. Os dois alunos desistentes relataram o seguinte:

\begin{abstract}
A1 - Os motivos que me levaram a sair dessa escola não é nada pessoal mais foi por causa da longa greve que se estendeu, então achei melhor eu ir terminar o ano letivo e quem sabe até o Ensino Médio em uma escola que tem um horário mais flexível para mim, estou estudando na UNIOrka/Cuiabá.
\end{abstract}

A2 - Os motivos que me levaram a desistir desse ano letivo foi por causa do meu trabalho, como eu sou autônomo resolvi abrir minha própria empresa e nesse momento não consigo assimilar o trabalho e escola, vou deixar assim para o próximo ano o meu retorno aos estudos.

$\mathrm{Na}$ prática, a fala dos dois estudantes que desistiram da escola evidencia que a desistência ou a evasão escolar se deu em função do imperativo histórico relativo à exploração da força de trabalho humana, justificada pela necessidade da sobrevivência, atributo intrínseco ao modo de produção desenvolvida pelo sistema capitalista, estabelece uma das formas de opressão, muito bem observada por Paulo Freire (2005), que transforma o homem em coisa/objeto, em ser acrítico e não pensante, de forma a desumanizá-lo.

Além das informações contidas nos gráficos, consideramos importante destacar as razões que levaram alguns estudantes que já no decorrer da pesquisa desistiram mais uma vez da escola. Durante a investigação, ao retornar à escola ficou comprometido em função de uma longa greve, ao entrar em contato com os alunos da escola $\mathrm{A}$, constatamos que dos oitos alunos que se propuseram a colaborar com a realização da pesquisa, dois deles haviam desistido da escola. A seguir, apresentamos a fala dos alunos desistentes justificando as razões para tal. 
As falas a seguir são de alunos das duas escolas investigadas e evidenciam suas visões no que se refere as suas percepções em relação ao currículo trabalhado na escola e as dificuldades enfrentadas por eles no seu cotidiano para conciliar estudo/trabalho/família.

\begin{abstract}
A3 - Como eu fiquei muito tempo fora da escola tenho dificuldade de acompanhar as matérias/conteúdos, que vocês professores chamam de currículo, principalmente as matérias de cálculos (matemática, física,...) e também a disciplina de inglês, por isso muitas vezes tive vontade de desistir, mais estou firme aqui e quero terminar pelo ao menos a Ensino Médio.
\end{abstract}

A4 - Eu para falar a verdade não sei essa coisa de currículo, acho muito complicado e ligava essa palavra a aquele papel que eu levava quando iria procurar emprego e só estou aqui para terminar o Ensino Médio e tentar conseguir um trabalho melhor.

A5 - Já desisti dos estudos duas vezes e estou aqui por sei que é através dos estudos que podemos construir um futuro melhor, pretendo terminar o Ensino Médio e fazer o ENEM para o curso de Direito e sei que tenho muito que aprender, por isso leio bastante pela internet.

A6 - Eu tive alguns problemas familiares, engravidei e esse foi o motivo para sair da escola, mais posso dizer que também foi um dos motivos que retornei e estou fazendo a EJA porque no meu trabalho eles exigiram que eu tivesse o Ensino Médio e pensando no meu futuro e no futuro da minha filha estou aqui estudando, mesmo com as dificuldades com o currículo/conteúdos trabalhados em sala de aula eu vou finalizar essa etapa.

A7 - Meu grande problema em estudar não é tanto o currículo trabalhado pela escola e sim sua exigência em relação ao horário de entrada, pois trabalho longe e dependo de ônibus, por isso por muitas vezes chego atrasado e tenho que esperar a segunda aula para entrar na escola, isso me atrapalha e tenho dificuldade em conciliar trabalho e estudo.

Fica perceptível o problema que os jovens têm para conciliar o tempo entre os estudos e o trabalho, característica presente nas duas escolas pesquisadas. Contudo, embora tenhamos clareza de que a educação é inerente à vida humana, e em sendo assim, ela tem sido concebida como um dos mecanismos de transformação e mudança da sociedade, embora seja responsável pela plena formação humana para a vida, temos clareza de que a educação por si só é insuficiente para realizar a transformação necessária na vida das pessoas que compõem a sociedade, a ponto de poder transformá-la.

A EJA carece de evidenciar o propósito de garantir não só o aumento de escolarização da classe trabalhadora, na atualidade composta por jovens e adultos acima de dezoito anos de idade, de maneira a inseri-los no mundo e no mercado de trabalho por meio da formação técnica, a fim de possibilitar não só sua sobrevivência, mas também ascensão econômica e social, a partir de uma "perspectiva de desenvolvimento e justiça social” (BRASIL, 2006, p. 2)

Nossa percepção é a de que, a educação só poderá produzir o efeito de plenitude se for compreendida e produzida como um ato de conhecimento, um ato político, um compromisso ético e uma experiência estética (FREIRE, 2003). 


\section{CONSIDERAÇÕES FINAIS}

A educação básica pautada no princípio da igualdade de direito ao conhecimento produzido pela humanidade, pode representar a conquista do acesso e permanência na escola daqueles que, pelos mais diversos motivos econômicos, políticos e sociais, não chegaram a frequentá-la na idade regular ou dela foram excluídos (MACHADO, 2008).

Este artigo, embora seja recorte de uma pesquisa de mestrado em andamento, evidencia alguns pontos constatados pela investigação, e que nos auxilia na compreensão do fenômeno, pertinente às tramas que envolvem a temática relativa à EJA.

A pesquisa permitiu a realização de uma reflexão sobre a importância da educação para qualquer cidadão, ator social pertencente à EJA, tendo em vista que na perspectiva de um processo formativo integral que esta modalidade busca cumprir com seu papel social, ultrapassando a dimensão do aumento do nível de escolaridade, promovendo na mesma perspectiva uma educação humana, crítica e transformadora, aliada à preparação para o mundo do trabalho, assim como para a continuidade dos estudos no ensino superior, caso seja desejo do estudante.

Muitas são as razões que motivam o retorno dos homens e mulheres à escola: para ajudar seus filhos com as tarefas, para acompanhar os filhos na escola no período noturno por não encontrar vaga no período diurno pelo perigo de deixar sua filha vir para a escola sozinha, para diminuir o tempo perdido, etc. Independente da razão quanto ao retorno à escola, uma certeza: O currículo da EJA evidencia uma formação para a prática da liberdade, tendo em vista que todo ato educativo é intencional, na EJA, a intenção está concebida nos sonhos e utopias de cada um e cada uma que acreditam na possibilidade de um mundo melhor.

A pesquisa evidencia que a EJA, embora se apresente como uma modalidade de ensino que abriga em si muitas lacunas e resquícios de uma sociedade perversa, no sentido de encampar e desenvolver uma educação que privilegia a competitividade que acaba por solapar, na prática política, as prerrogativas de cidadania que sustentam o ideário de educação em sua plenitude, cumpre com o seu papel, ao possibilitar aos homens e mulheres pertencentes a esta modalidade a possibilidade de melhoria das condições de vida.

\section{REFERÊNCIAS}

APPLE, Michael. Ideologia e currículo. 3 ed. Porto Alegre: Artmed, 2006

ARANHA, Maria Lúcia de Arruda. História da educação. 2. ed. São Paulo: Moderna. 
ARROYO, Miguel G. "Os educadores, seus direitos e o currículo". In: MOREIRA, Antonio Flávio e ARROYO, Miguel. Indagações sobre o currículo. Brasília: Departamento de Política de Educação Infantil e Ensino Fundamental, nov. 2006.

BELLO, José Luiz de Paiva. Movimento Brasileiro de Alfabetização - MOBRAL.

História da Educação no Brasil. Período do Regime militar. Pedagogia em foco, Vitória 1993, Disponível em < http://www.pedagogiaemfoco.pro.br/heb10a.html >. Acesso em: 03 de julho de 2019.

BOGDAN, Robert; BIKLEN, Sari. Investigação Qualitativa em educação: uma introdução à teoria e aos métodos. Porto, Portugal: Porto Ed., Coleção Ciências da Educação, 1994.

BRASIL. Lei de Diretrizes e Bases da Educação Nacional. - LDB. Lei No 9394/96. Brasília, 2007.

BRASIL. Ministério da Educação. Programa de Integração da Educação Profissional ao Ensino Médio na Modalidade de Educação de Jovens e Adultos - Proeja: Documento Base. Brasília-DF: MEC, fev. de 2006.

BRASIL. Constituição Federal BRASIL. Programa Brasil Profissionalizado. Brasília. 2007. Disponível em:http://portal.mec.gov.br/index2.

php?option=com_content\&view=article\&id=12325\&Item id=663 Acesso em 15/07/19.

FREIRE, Paulo. Pedagogia da Autonomia. saberes necessários à prática educativa. São Paulo: Paz e Terra, 2003.

FREIRE, Paulo. Pedagogia do Oprimido. Rio de Janeiro: Paz e Terra, 2005, 42. ed.

FREIRE, Paulo. Pedagogia da Autonomia: saberes necessários à prática educativa. São Paulo: Paz e Terra, 1996.

GHIRALDELLI JUNIOR, Paulo. História da educação brasileira/Paulo Ghiraldelli JR. 2. ed. São Paulo: Cortez, 2006. Brasília, 1998.

LAKATOS, Eva Maria; MARCONI, Marina de Andrade. Metodologia Científica. 26. ed., São Paulo: Atlas, 1991.

MARX, Karl.; ENGELS, Friedrich. A Ideologia Alemã. Tradutor Luis Cláudio de Castro e Costa. Martins Fontes: São Paulo, 2002.

LÜDKE, Menga; ANDRÉ, Marli. Pesquisa em Educação: abordagens qualitativas. São Paulo, EPU, 1986.

MACHADO, Lucília Regina de Souza. Diferenciais inovadores na formação de professores para a educação profissional. Revista Brasileira da Educação Profissional e Tecnológica, Brasília, v. 1, $\mathrm{n}^{\circ} 1,2008$.

MCLAREN, Peter. Multiculturalismo crítico. São Paulo: Cortez, 1999. 
MINAYO, Maria Cecília de Souza. (org.). Pesquisa Social. Teoria, método e criatividade. 18 ed. Petrópolis: Vozes, 2001.

MINISTÉRIO DA EDUCAÇÃO. Diretrizes Curriculares Nacionais Gerais da Educação Básica/ Secretaria de Educação Básica. Diretoria de Currículos e Educação Integral. Brasília: MEC, SEB, DICEI, 2013. Disponível em: http://portal.mec.gov.br/docman/julho2013-pdf/13677-diretrizes-educacao-basica-013-pdf/file Acesso em 15-07-2019.

MOREIRA, Antonio Flávio Barbosa; SILVA, Tomaz Tadeu. (Org.). Currículo, cultura e sociedade. 2. ed. São Paulo: Cortez, 1997.

MOREIRA, Antônio Flávio Barbosa Moreira; CANDAU, Vera Maria (Orgs.). Indagações sobre currículo: currículo, conhecimento e cultura. Ministério da Educação. Secretaria de Educação Básica. Brasília, 2007

MORGAN, D.L; KRUEGER, R. A. Quando usar grupos de foco e por quê. Em: Grupos de foco bem sucedidos: avançando o estado da arte. [s.1.] Sage Focus Editions, 1993.

OLIVEIRA, Inês Barbosa de. Reflexões acerca da organização curricular e das práticas pedagógicas na EJA. Educ. rev. [online]. n.29, p.83-100,2007.

OLIVEIRA, Inês Barbosa de. Organização curricular e práticas pedagógicas na EJA: algumas reflexões. In: PAIVA, Jane; OLIVEIRA, Inês Barbosa de. (Orgs.) Educação de jovens e Adultos, Petrópolis: DP et Alii, 2009.

OLIVEIRA, Claudimercia Lima de. Descortinando a EJA e suas práticas educacionais: o papel da educação de jovens e adultos no Brasil como modalidade diferenciada de ensino e emancipação dos sujeitos. Bahia. 2015.

PAIVA, Vanilda Pereira. Educação popular e educação de adultos. 5. ed. São Paulo: Loyola, 1987.

Recebido em: 08 de outubro de 2019.

Aprovado em: 01 de dezembro de 2019. 